\title{
Production Decoupling under US Farm Programs
}

\author{
Charles B. Moss ${ }^{1}$, Andrew Schmitz ${ }^{1}$, Troy G. Schmitz ${ }^{2}$ \\ ${ }^{1}$ Food and Resource Economics, IFAS, University of Florida, Gainesville, USA; ${ }^{2}$ Morrison School of Agribusiness and Resource \\ Management, Arizona State University, Mesa, USA. \\ Email: cbmoss@ufl.edu, aschmitz@ufl.edu, tschmitz@asu.edu
}

Received September $5^{\text {th }}, 2013$; revised November $3^{\text {rd }}, 2013$; accepted December $2^{\text {nd }}, 2013$

Copyright (C 2014 Charles B. Moss et al. This is an open access article distributed under the Creative Commons Attribution License, which permits unrestricted use, distribution, and reproduction in any medium, provided the original work is properly cited. In accordance of the Creative Commons Attribution License all Copyrights @ 2014 are reserved for SCIRP and the owner of the intellectual property Charles B. Moss et al. All Copyright (c) 2014 are guarded by law and by SCIRP as a guardian.

\begin{abstract}
The loan rate and target price are key ingredients in US farm policy. Empirical models of the effect of US agricultural policy are based on different degrees of decoupling between price supports and production. Theoretically, rational producers will make decisions based on the loan rate rather than the target price. Therefore, models which are estimated based on a target price specification could significantly overestimate the distortionary impact of policy on resource use and production.
\end{abstract}

\section{KEYWORDS}

\section{Decoupling; Loan Rate; Price Suppression; Target Price}

\section{Introduction}

Historically, agricultural policy in the United States has used several mechanisms to support agricultural income. During the 1950s and 1960s, farm prices were supported using a variety of marketing instruments coupled with acreage allotments. Specifically, the Commodity Credit Corporation made non-recourse loans at a stated loan rate for program crops. Under this program, the farmer could simply forfeit the crop in payment of the loan. This led to the accumulation of a large stock of surplus grain. In the 1970 s through the 1980s, the agricultural program shifted slightly. The acreage allotments were changed to base acreages. The Commodity Credit Corporation still maintained a defacto price floor (and typically accumulated stocks). However, an additional instrument referred to as the deficiency payment was introduced that provided for direct payments based on the difference between a mandated target price and either the higher of the loan rate or the market price over a stated marketing period. The target price for a basic farm commodity in the United States is established by law as a mechanism to support agricultural income (Schmitz et al. 2010 [1]). The loan rate is the price floor set in agricultural policy legislation that grew out of the operation of the Commodity Credit Corporation, which took commodities as collateral at the loan rate in its non-recourse loan program (Schmitz et al. 2010 [1]). The farmer then received a deficiency payment defined as the difference between the target price and the greater of either the loan rate or the market price times the number of base acres (adjusted for setaside or mandatory acreage reductions) times program yields. The present value of these deficiency payments formed the basis of the production flexibility contracts or Agricultural Market Transaction Act payments under the FAIR Act and remained in the countercyclical payments in more recent agricultural legislation.

This paper examines, theoretically and empirically, whether farmers respond to the loan rate or the target price under agricultural policy regimes before the passage of the Federal Agricultural Improvement and Reform (FAIR) Act of 1996. The implications of farmer response to agricultural policy are important when considering the successor of the Food, Conservation, and Energy Act of 2008. There is little agreement among researchers as to whether producers respond to the target price, the loan rate, or somewhere in between when making production decisions. The terminology used by the World Trade Organization (WTO) regarding "significant price suppression" is ambiguous and provides little guidance as to where producers respond to the price con- 
tinuum. Nor does the WTO offer any kind of empirical gauge about the degree of decoupling.

\section{Past Results}

Several studies have empirically modeled the impact of US policy. Schmitz, Schmitz, and Dumas (1997 [2]) estimate the impact of US cotton policy, assuming that farmers make production decisions based on the target price. Later, Schmitz, Rossi, and Schmitz (2007 [3]) show the empirical results under a loan rate specification. Empirical results by Westcott, Young, and Price (2002 [4]); Anton and Le Mouel (2003 [5]); Goodwin and Mishra (2005 [6]); and Lin and Dismukes (2005 [7]) are based on producer supply price expectations that fall between the target price and the loan rate.

To highlight the debate, consider the impact of the US cotton policy, which was the basis for a WTO lawsuit launched by Brazil against the United States (Powell and Schmitz 2005 [8]). The impact depends on several interrelated factors: how input subsidies interact with producer price supports, producer price expectations, and the extent to which price supports are decoupled from production. Cotton subsidies have a direct impact on world cotton prices, depending on the extent to which price supports are coupled to production (Schmitz, Rossi, and Schmitz 2007 [3]). Table 1 gives the results of the impact of the US cotton policy on world cotton prices under both target price and loan rate specifications. Under the target price specification, the average percentage reduction in world cotton prices over free trade is 20.5 percent for the crops years 1999 through 2004. On the other hand, under the loan rate model, the world cotton price impact is much less at 12.4 percent (Schmitz, Rossi, and Schmitz 2007 [3]).

\section{Theoretical Framework}

\subsection{Production Decisions and Resource Use}

The amount of resources used in production generally depends on producer price expectations. In a simple model framework, consider Figure 1, where $S$ is supply, $D_{d}$ is domestic demand, and $T_{D}$ is total demand. If producers make decisions at the target price $p_{1}$ production is $q_{1}$. The deficiency payment from the government is $\left(p_{1} p_{2} b a\right)$ and variable costs total $\left(y x q_{1} a\right)$.

Suppose instead, producers make production decisions based on the loan rate $p_{2}$. Planned production falls to $q_{2}$. Variable costs are $\left(y x q_{2} b^{\prime}\right)$. Total variable costs are reduced by $\left(b^{\prime} q_{2} q_{1} a\right)$ under the loan rate response mod$\mathrm{el}^{1}$.

In this formulation, producers gain by making deci

${ }^{1}$ Note, as shown, that it is possible for an exporter to become an importer under a loan rate model versus a target price specification.
Table 1. Free trade: US cotton target price and loan rate specifications, 1999-2004.

\begin{tabular}{ccc}
\hline Crop Year & $\begin{array}{c}\text { Target Price } \\
\text { (freetrade price } \\
\text { difference-\%) }\end{array}$ & $\begin{array}{c}\text { Loan Rate } \\
\text { (freetrade price } \\
\text { difference-\%) }\end{array}$ \\
\hline $1999-2000$ & 29.3 & 20.5 \\
$2000-2001$ & 19.9 & 10.3 \\
$2001-2002$ & 20.7 & 13.6 \\
$2002-2003$ & 17.4 & 8.7 \\
$2003-2004$ & 15.2 & 8.7 \\
Average & 20.5 & 12.4 \\
\hline
\end{tabular}

Source: Schmitz, Rossi, and Schmitz (2007 [3]).

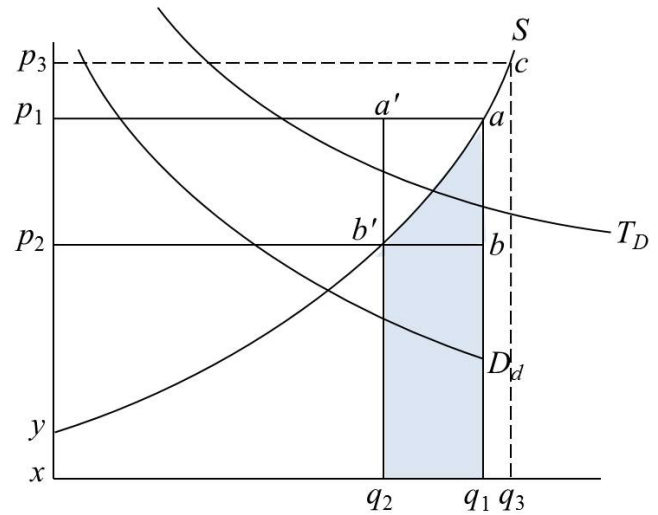

Figure 1. Target price and loan rate specifications.

sions based on the target price. The net welfare gain from basing decisions on price $p_{1}$ rather than price $p_{2}$ is $\left(p_{1} p_{2} b^{\prime} a\right)$ in spite of the added variable costs $\left(b^{\prime} q_{2} q_{1} a\right)$.

From a resource use standpoint, consider again Figure 1 , where $p_{3}$ represents a price expectation on the part of producers which is an expected price above the exported target price $p_{1}$. At price $p_{3}$, output is expected to increase to $q_{3}$. As comparison, if in the previous year $t-1$, producers based decisions at the loan rate price $p_{2}$, then at time $t$ with a price expectation of $p_{3}$, variable costs increase by $\left(b^{\prime} q_{2} q_{3} c\right)$ as output increased from $q_{2}$ to $q_{3}$.

However, if at time $t-1$, the price expectation was the target price $p_{1}$, then at time $t$, the variable costs only increased by $\left(a q_{1} q_{3} c\right)$ as output only increased from $q_{1}$ to $q_{3}$.

\subsection{Loan Rate or Target Price}

The question of whether the loan rate or target price affects the quantity of a good produced can be traced to the firm's production decision. Assume that producer chooses the level of production by determining the level of a single input that maximizes profit expressed as 


$$
\operatorname{Max}_{x_{t}} P_{t} f\left(x_{t}\right)-w_{t} x_{t}
$$

where $p_{t}$ is the output price at time $t, f\left(x_{t}\right)$ is the standard primal production function given the level of the variable input $x_{t}$, and $w_{t}$ is the price of the input at time $t$. The effect of the loan rate and target price on the quantity supplied is dependent on how each policy variable affects output prices in Equation (1). As a starting point, consider the effect of the loan rate which the farmer receives if the market price is higher than the loan rate. Assuming that the farmer maximizes expected profit, Equation (1) becomes

$$
\operatorname{Max}_{x_{t}} E_{t}\left[\max \left[P_{t}, P_{L t}\right] f\left(x_{t}\right)-w_{t} x_{t}\right]
$$

where $E_{t}[$.$] denotes the expectation function given in-$ formation available at time $t$ and $P_{L t}$ is the loan rate for the crop at time $t$. It is trivial to show that expected profit and level of the variable input increases as the loan rate increases. The debate in the literature involves the effect of the target price.

To develop the effect of the target price we note that the target price is paid on base acres for program or proven yields. Thus, deficiency payment at time $t$ can be written as

$$
\begin{aligned}
& D_{t}\left(x_{t-1}, x_{t-2}, \cdots x_{t-5}\right) \\
& =\left(1-\alpha_{t}\right) \max \left[0, P_{T t}-\max \left[P_{t}, P_{L t}\right]\right] \times \tilde{y}_{t}\left(x_{t-1}, x_{t-2}, \cdots x_{t-5}\right)
\end{aligned}
$$

where $D_{t}$ is the deficiency payment, $\alpha_{t}$ is the set-aside effective in year $t, P_{T t}$ is the target price, and $\tilde{y}_{t}\left(x_{t-1}, x_{t-2}, \cdots x_{t-5}\right)$ is the program yield. The controversy on the effect of the target price is dependent on the definition of the program yield. Typically, the farmer could choose to rely on the county average yield or choose to prove another yield based on average historical production. Hence, we represent the program yield as

$$
\tilde{y}_{t}\left(x_{t-1}, x_{t-2}, \cdots x_{t-5}\right)=\max \left[\bar{y}_{C t}, \sum_{i=1}^{5} a_{i} f\left(x_{t-i}\right)\right]
$$

where $\bar{y}_{C t}$ is the average crop yield for the county, $a_{i}$ is a weight for computing the average program yield (one case would be the use of an Olympic Average to construct program yields; hence the $a_{i}$ is set to zero for the high and low yield with the remaining $a_{i}=1 / 3$ ).

Using this formulation for the deficiency payment, the producer's problem then becomes

$$
\begin{aligned}
\operatorname{Max}_{x_{t}} E_{t} & {\left[\max \left[P_{t}, P_{L t}\right] f\left(x_{t}\right)\right.} \\
& \left.-w_{t} x_{t}+D_{t}\left(x_{t-1}, x_{t-2}, \cdots x_{t-5}\right)\right] .
\end{aligned}
$$

Under this formulation, the current production decision does not affect the deficiency payment received by the farmer. To capture the effect of production decisions on the deficiency payment, we extend Equation (5) by considering the present value of production decisions

$$
\underset{x_{t}, x_{t+1}, \cdots}{\max } E_{t}\left[\sum_{t=0}^{N} \beta^{i}\left(\max \left[P_{t}, P_{L t}\right] f\left(x_{t}\right)-w_{t} x_{t}+D_{t}\left(x_{t-1}, x_{t-2}, \cdots x_{t-5}\right)\right)\right]
$$

where $\beta=1 /(1+r)$ is the single period discount rate. Hence, taking the first-order condition of Equation (6) yields

$$
E_{t}\left[\max \left[P_{t}, P_{L t}\right] \frac{\partial f\left(x_{t}\right)}{\partial x_{t}}-w_{t}+\sum_{i=1}^{5} \beta^{i} \frac{\partial D_{t+i}\left(x_{t+i-1}, x_{t+i-2}, \cdots x_{t+i-5}\right)}{\partial x_{t}}\right] .
$$

If we assume that the $f\left(x_{t}\right)>\bar{y}_{C t}$ for $\forall x_{t} \in N\left(x_{t}^{*}\right)$ where $x_{t}^{*}$ is the optimum input level (where $N\left(x_{t}^{*}\right)$ denotes an open neighborhood around $x_{t}^{*}$ ), the effect of the deficiency payment on the optimum input level becomes

$$
\begin{aligned}
E_{t}\left[\sum_{i=1}^{5} \beta^{i} \frac{\partial D_{t+i}\left(x_{t+i-1}, x_{t+i-2}, \cdots x_{t+i-5}\right)}{\partial x_{t}}\right]= \\
\sum_{i=1}^{5} \beta^{i} E_{t}\left[\alpha_{t+i} \max \left[0, P_{T t+i}-\max \left[P_{t+i}, P_{L t+i}\right]\right]\right] a_{i} \frac{\partial f\left(x_{t}\right)}{\partial x_{t}} \geq 0
\end{aligned}
$$

Given that $\max \left[0, P_{T t+i}-\max \left[P_{t+i}, P_{L t+i}\right]\right] \geq 0$, the supply of output will be greater for Equations (7) and (8) (with deficiency payments) than for Equation (2) (with only the loan rate). However,

$$
\begin{aligned}
& \tilde{x}_{t} \Leftrightarrow \operatorname{Max}_{\tilde{x}_{t}} E_{t}\left[\max \left[P_{t}, P_{T t}\right] f\left(x_{t}\right)-w_{t} x_{t}\right] \geq \\
& x_{t}^{*} \Leftrightarrow \operatorname{Max}_{x_{t}, x_{t+1}, \cdots} E_{t}\left[\sum_{t=0}^{N} \beta^{i}\left(\max \left[P_{t}, P_{L t}\right] f\left(x_{t}\right)-w_{t} x_{t}+D_{t}\left(x_{t-1}, x_{t-2}, \cdots x_{t-5}\right)\right)\right] \geq \\
& \hat{x}_{t} \Leftrightarrow \operatorname{Max}_{x_{t}} E_{t}\left[\max \left[P_{t}, P_{L t}\right] f\left(x_{t}\right)-w_{t} x_{t}\right]
\end{aligned}
$$


where $\tilde{x}_{t}$ is the optimal level of input used when the farmer realizes the target price (i.e., farmers respond to the target price directly), $x_{t}^{*}$ is the optimal level of input used when the farmer realizes returns from the target price from the deficiency payment over time, and $\hat{x}_{t}$ is the optimal level of input used when the farmer only responds to the loan rate because $\sum_{i=1}^{5} \beta^{i} a_{i} \ll 1$.

In the FAIR Act of 1996, the Agricultural Market Transaction Act payments were fixed so that $\partial D_{t}(.) / \partial x_{t}=0$, implying $x_{t}^{*}=\widehat{x}_{t}$. While some adjustment in base yield was allowed with the passage of the Farm Security and Rural Investment Act of 2002, the countercyclical payments followed the fixed program yield formulation introduced in 1996.

Building on this formulation, Figure 2 illustrates both the loan rate and target price model for cotton. Domestic demand is given by $D_{d}$ and supply is given by $S$. Under the loan rate-based decoupled scenario, the equilibrium price and quantity are $p_{l}$ and $q_{l}$. The coupled loan deficiency payments (LDPs) to producers equal $\left(p_{l} p_{i} f b\right)$, while the decoupled countercyclical payments equal $\left(p_{t} p_{l} b a^{\prime}\right)$ if producers respond to the loan rate, $p_{l}$, and not to the net target price, $p_{t}$. The producers gain from price supports equal $\left(p_{t} p_{l} b a^{\prime}\right)$. The magnitude of these producer rents for cotton is $\$ 1.74$ billion for 2002 (Schmitz, Rossi, and Schmitz 2007 [3]).

Now we show the effects if the producers respond to the target price set rather than the loan rate. In the literature there is considerable confusion as to whether farmers respond to the loan rate, target price, or to some price in between. However, as we show, farmers should make decisions based on the loan rate and not the target price (Figure 2). Given that the countercyclical payment is determined by base acres and base yield, the amount of payment is fixed with respect to input decisions. That is, farmers cannot capture ( $\left.\mathrm{a}^{\prime} \mathrm{ba}\right)$ by responding to the target price rather than the loan rate. Since the transfer of countercyclical payments from taxpayers to farmers does not affect production, the comparison of the welfare impacts under the loan rate and the target price is somewhat trivial.

Consider the effects if producers responded to the target price rather than the loan rate. In this case, producers would suffer a loss of (a'ba). Specifically, if the producers attempt to increase production in response to the target price, they would only receive the loan rate $p_{l}$; hence, they would lose the cost of production on $\left(q_{\mathrm{t}}-q_{\mathrm{l}}\right)$ units of output. By attempting to respond to the target price, farmers add the cost $\left(b q_{1} q_{t} a\right)$. However, they only receive revenue based on the loan rate $\left(\mathrm{b} q_{1} q_{\mathrm{t}} \mathrm{b}^{\prime}\right)$. Since the market price at this additional quantity falls to $p_{0}$, the farmer now receives $\left(p_{0} 0 q_{\mathrm{t}} \mathrm{e}\right)$ from the market and $\left(p_{1} p_{0} \mathrm{eb}^{\prime}\right)$ as a loan payment.

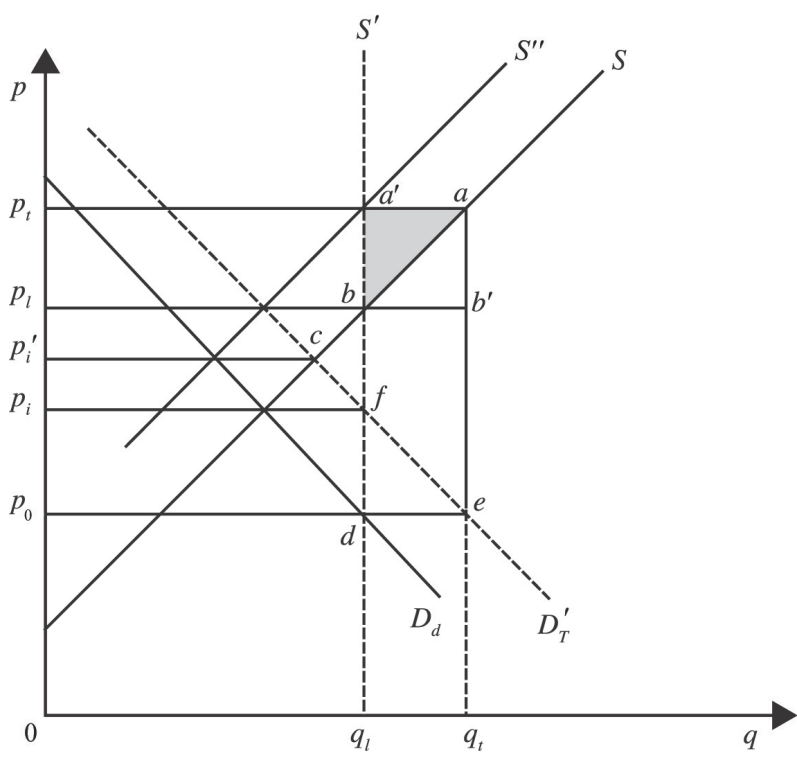

Source: Schmitz et al. [1, p 269].

Figure 2. Loan rate model and target price model.

\section{Summary and Conclusions}

The impact of US agricultural subsidies is increasingly being scrutinized, especially in view of the successful Brazilian challenge to US cotton subsidies in the WTO. The impact of US subsidies can be significant (Powell and Schmitz 2005 [8]), depending on the degree of decoupling between production and price supports. Farmers' decisions based on loan rates yield outcomes that are more decoupled than those based on target prices. Our theoretical results show that rational producers will make production decisions based on loan rates. This is important since a WTO ruling may incorrectly find a high degree of policy coupling if they rely on results based on a target price specification when the true empirical results should be grounded on a loan rate phenomenon. The significant price suppression terminology used in the WTO ruling unfortunately does not provide guidance as to where producers respond to the price continuum in our model. Moreover, the findings in the WTO rulings do not give an empirical gauge as to the degree of decoupling. For example, the impact of US cotton policy on world prices can range from between 20.5 and 12.4 percent, depending on the degree of decoupling assumed in empirical specification.

Most of the models that estimate the impact of US agricultural policy focus more heavily on price impacts rather than resource use impacts. As our results show, the resource impact depends on several factors, including producer price expectations and supply elasticities. If the finding, for example, by the WTO on price suppression is correct, then it appears that, at least in the cotton case, many more resources were used than would be under a 
free market setting.

\section{REFERENCES}

[1] A. Schmitz, C. B. Moss, T. G. Schmitz, H. W. Furtan, and H. C. Schmitz, "Agricultural Policy, Agribusiness, and Rent-Seeking Behaviour," 2nd Edition, University of Toronto Press, Toronto, 2010.

[2] T. G. Schmitz, A. Schmitz and C. Dumas, "Gains from Trade, Inefficiency of Government Programs, and the Net Economic Effects of Trading," Journal of Political Economy, Vol. 105, No. 3, 1997, pp. 637-647. http://dx.doi.org/10.1086/262086

[3] A. Schmitz, F. Rossi and T. Schmitz, "US Cotton Subsidies: Drawing a Fine Line on the Degree of Decoupling," Journal of Agricultural and Applied Economics, Vol. 39, No. 1, 2007, pp. 135-149.

[4] P. Westcott, C. Young and J. Price, "The 2002 Farm Act: Provisions and Implications for Commodity Markets," AIB778, USDA/ERS, Washington DC, 2002.

[5] J. Anton and C. Le Mouel, "Do Countercyclical Payments in the FSRI Act Create Incentives to Produce?” Proceedings of the 25th International Conference of Agricultural Economists, Durban, 2003.

http://ageconsearch.umn.edu/bitstream/25811/1/cp03an02 .pdf

[6] B. Goodwin and A. Mishra, "Another Look at Decoupling: Additional Evidence on the Production Effects of Direct Payments," American Journal of Agricultural Economics, Vol. 87, No. 5, 2005, pp. 1200-1210. http://dx.doi.org/10.1111/j.1467-8276.2005.00808.x

[7] W. Lin and R. Dismukes, "Risk Considerations in Supply Response: Implications for Countercyclical Payments' Production Impact," Proceedings of the American Agricultural Economics Association Conference, Providence, 2005.

http://ageconsearch.umn.edu/bitstream/19304/1/sp05li09. pdf

[8] S. Powell and A. Schmitz, "The Cotton and Sugar Subsidies Decisions: WTO's Dispute Settlement System Rebalance Agreement on Agriculture," Drake Journal of Agricultural Law, Vol. 10, No. 2, 2005, pp. 287-330. 